\title{
Thoracic impalement after ultralight aircraft crash
}

\author{
Douglas M. Bowley, FRCS, Mark P. Gordon, MBBCh, and Kenneth D. Boffard, BSc (Hons), FRCS, FRCS (Edin), FACS, \\ Johannesburg, Republic of South Africa
}

I mpalement injuries make rare, if spectacular, appearances at trauma centers. We describe the successful management of a left-sided thoracic impalement injury after an ultralight aircraft crash.

\section{Clinical Summary}

A 40-year-old man was taking off in an ultralight aircraft, which stalled and plunged to the ground. The tail boom broke off on impact and impaled him through the left side of the chest. Paramedics discovered the pilot fully conscious; no attempt was made to remove the boom, but specialized cutting equipment was necessary to shorten it for transport. On arrival the patient's breathing was rapid and shallow, and the systolic blood pressure was $90 \mathrm{~mm}$ $\mathrm{Hg}$ with a pulse rate of 135 beats/min. An intercostal drain was placed after a chest radiograph was performed, and the patient was transferred directly to the operating room without further investigative studies. He was positioned at the edge of the operating table (Figure 1), which enabled him to lie supine and a double-lumen endotracheal tube to be inserted. The patient was turned (Figure 2) and a generous posterolateral thoracotomy incision was made, connecting entry and exit wounds. The tail boom was transfixing the lower lobe of the lung, although the diaphragm remained intact. The hilar vessels were dissected and controlled, and the boom was cautiously removed. The lower lobe of the left lung was damaged beyond repair, so a lobectomy was undertaken and the pleural cavity was extensively irrigated. The chest wall defects were debrided, but primary closure was possible. Two $36 \mathrm{~F}$ intercostal drains were placed, and the thoracotomy wound was closed routinely. The patient made an uneventful recovery and was well when he was reexamined 6 months after the incident.

\section{Discussion}

According to the International Civil Aviation Authority, the incidence of fatal aircraft crashes has consistently declined during the past 10 years. In 1991 there were 1.7 fatal crashes per million flights; this was reduced to 0.85 fatal crashes per million flights in $2000 .{ }^{1}$ Survivors are rare after civilian aircraft crashes; in one

From the Trauma Unit, Johannesburg Hospital, and the Department of Surgery, University of the Witwatersrand Medical School, Johannesburg, Republic of South Africa.

Received for publication Aug 8, 2002; accepted for publication Aug 22, 2002.

Address for reprints: Professor K. D. Boffard, Johannesburg Hospital Trauma Unit, Postnet Suite 235, Private Bag X2600, Houghton, 2041, South Africa (E-mail: trauma@mweb.co.za).

J Thorac Cardiovasc Surg 2003;125:954-5

Copyright $\odot 2003$ by The American Association for Thoracic Surgery $0022-5223 / 2003 \$ 30.00+0$

doi: $10.1067 / \mathrm{mtc} .2003 .200$ study from New Zealand, ${ }^{2}$ the rate for hospitalization was 2.45 per 100,000 flight hours. Most fatalities have involved injury to multiple body regions, with at least one injury being sufficient in itself to cause death in $48 \%$ of cases. Among patients who arrive alive at the hospital later, the lower extremities (23\%), spine (20\%), and head and face (18\%) are the body regions most commonly injured, with fractures being predominant. ${ }^{2}$ Although most fatalities and severe injuries occur in fixed-wing and rotary-wing aircraft, the highest rates are seen with ultralight and home-built aircraft. ${ }^{2}$ In a recent report from the United States, home-built aircraft accounted for $10 \%$ of the crashes and carried a higher per crash fatality rate, despite accounting for only $3 \%$ of all hours flown. Crashes caused by mechanical failure and crashes on takeoff and climb are more common in ultralight aircraft than in general aviation. ${ }^{3}$

Ultralight crashes occur for two main reasons: aircraft related and pilot related. Aircraft-related defects can be regulated for by statutory authorities; however, the second variable is more difficult to control by legislation. The users of ultralight aircraft have been described as "wanting all the thrills of flying with none of the hard work, training, and maturity required to become a professional or military pilot."4

Although reported protocols for management of impalement injury are based entirely on anecdote, there is uniformity in the suggested approach. -10 $^{-10}$ Thoracic impalements are most commonly right sided, presumably because of the reduced risk of striking the heart or great vessels on that side. ${ }^{8}$ Patients who survive to reach the hospital are a self-selected group; thus their chances of survival are high, because the probability is that organ injury is limited to the lung and that the cardiovascular system has been largely spared by the penetrating object. 5,8

Cautious extrication and rapid transportation are vital, with minimal manipulation of the impaled object. ${ }^{9}$ The object should be left in situ to avoid loss of tamponade effect. ${ }^{6,7}$ Although most reports stress that time should not be wasted with radiographic or other time-consuming studies, the surgical approach may be guided by selected investigations, including thoracic computed tomography and aortic angiography when patients are in stable condition. ${ }^{6}$ Unorthodox positioning or incisions may be required, and skilled anesthetic provision is essential, because the patient may not be able to be positioned supine and a double-lumen endotracheal tube may be required.5,6 Wide exposure is mandatory, and the object should be extracted only after appropriate vascular control has been achieved.9,10 All necrotic tissue should be resected, but care should be taken to preserve viable lung, because an expanded lung is good protection against empyema. ${ }^{9}$ Complete closure of the chest should be attempted; however, delayed plastic reconstruction of the thoracic defect may be required. ${ }^{5,9} \mathrm{~A}$ great deal of force is required to impale the thorax, and there is often extensive local tissue destruction with elements of both blunt and penetrating injury. ${ }^{10}$ Impalement wounds are often grossly contaminated, by soil pathogens; appropriate surgical de- 


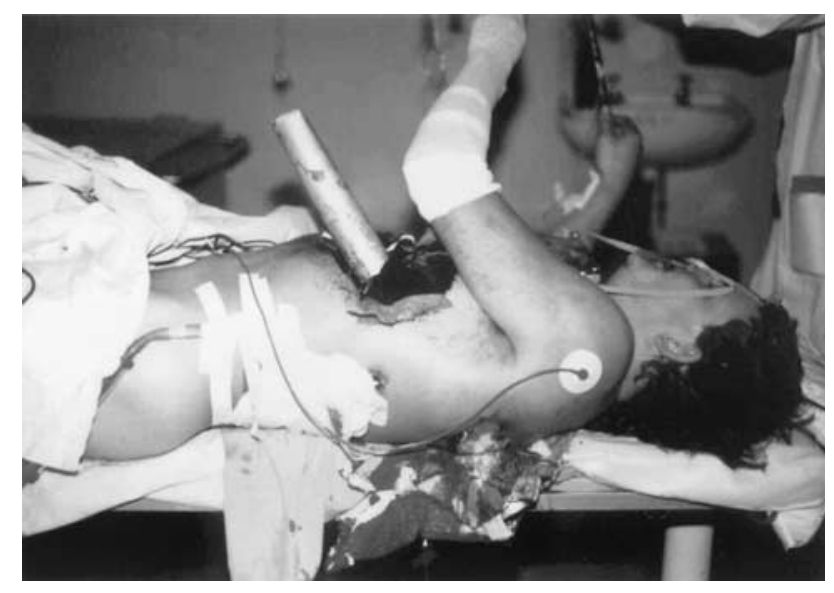

Figure 1. Left-sided thoracic impalement by tail boom of ultralight aircraft.

bridement, irrigation, and antibiotic and tetanus prophylaxis are therefore mandatory. ${ }^{7}$ Even after massive thoracic impalement, a coordinated effort from the crash scene to hospital, coupled with adherence to a common sense surgical approach, can lead to a good outcome.

\section{References}

1. Airline safety [editorial]. Flight Int. 2002;161:40-1.

2. Chalmers DJ, O'Hare DP, McBride DI. The incidence, nature, and severity of injuries in New Zealand civil aviation. Aviat Space Environ Med. 2000;71:388-95.

3. Hasselquist A, Baker SP. Home-built aircraft crashes. Aviat Space Environ Med. 1999;70:543-7.

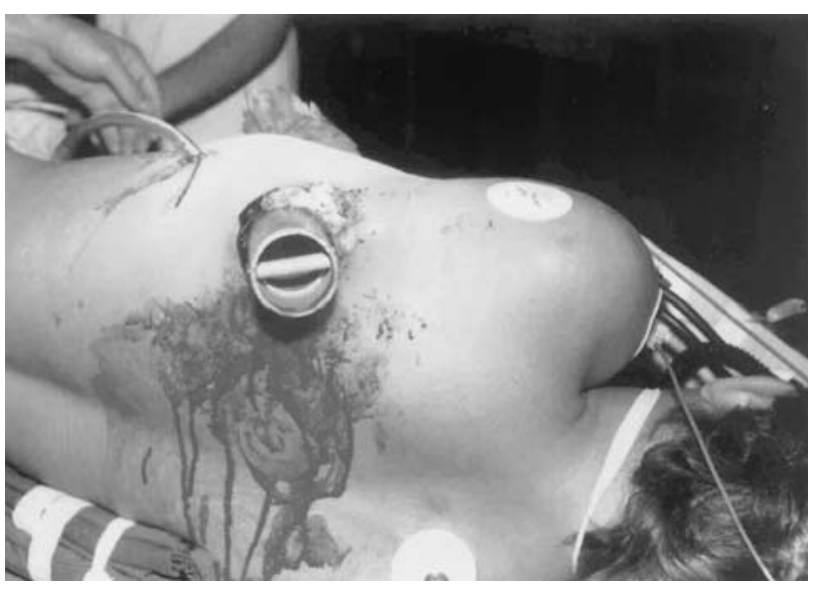

Figure 2. Patient has been turned to facilitate thoracotomy.

4. Copeland AR. Ultralight aircraft fatalities: report of five cases. Am J Forensic Med Pathol. 1987;8:296-8.

5. Cartwright AJ, Taams KO, Unsworth-White MJ, Mahmood N, Murphy PM. Suicidal nonfatal impalement injury of the thorax. Ann Thorac Surg. 2001;72:1364-6.

6. Chui WH, Cheung DL, Chiu SW, Lee WT, He GW. A non-fatal impalement injury of the thorax. J R Coll Surg Edinb. 1998;43:419-21.

7. Horowitz MD, Dove DB, Eismont FJ, Green BA. Impalement injuries. J Trauma. 1985;25:914-6.

8. Robicsek F, Daugherty HK, Stansfield AV. Massive chest trauma due to impalement. J Thorac Cardiovasc Surg. 1984;87:634-6.

9. Romero LH, Nagamia HF, Lefemine AA, Foster ED, Wysocki JP, Berger RL. Massive impalement wound of the chest: a case report. J Thorac Cardiovasc Surg. 1978;75:832-5.

10. Thomson BN, Knight SR. Bilateral thoracoabdominal impalement: avoiding pitfalls in the management of impalement injuries. J Trauma. 2000;49:1135-7. 